\title{
Opinion
}

\section{Paediatric Virology and respiratory syncytial virus: An interview with Honorary Senior Lecturer in Paediatric Infectious Diseases Dr Simon B. Drysdale (St. George's, University of London, UK)}

\author{
IOANNIS N. MAMMAS ${ }^{1-3}$ and DEMETRIOS A. SPANDIDOS ${ }^{1}$ \\ ${ }^{1}$ Laboratory of Clinical Virology, School of Medicine, University of Crete, 71003 Heraklion; ${ }^{2}$ First Department of Paediatrics, \\ University of Athens School of Medicine, 11527 Athens; ${ }^{3}$ Paediatric Clinic, Aliveri, 34500 Island of Euboea, Greece
}

Received July 22, 2019; Accepted August 26, 2019

DOI: $10.3892 /$ etm.2019.7947

\begin{abstract}
Dr Simon B. Drysdale, Consultant and Honorary Senior Lecturer in Paediatric Infectious Diseases at St. George's University Hospitals NHS Foundation Trust and St. George's, University of London, is one of the most talented early career academic specialists in Paediatric Infectious Diseases in the United Kingdom. His main research interest is respiratory syncytial virus (RSV); he is particularly interested in understanding the host susceptibility to RSV, the management of RSV infection and associated health economics and the development of treatments and immunisations/vaccines, which are currently lacking. According to Dr Drysdale, RSV is a significant cause of morbidity and mortality among young infants and older adults, particularly those with co-morbidities. While there is ample RSV epidemiological and healthcare cost data available for young infants and children, more data is required for older children and adults. There are currently several antiviral medications for the treatment of RSV infection in development; however, none have yet progressed beyond Phase 2 clinical trials. Multiple types of novel therapeutic molecules have been developed, including fusion and non-fusion inhibitors and polymerase inhibitors aimed at various RSV targets, such as the F protein and RNA polymerase. In recent years, great strides have been made with regards to an RSV vaccine or monoclonal antibody, with $>40$ candidates currently in development. A maternal RSV vaccine, which just completed a Phase 3 trial, was shown to have $44 \%$ efficacy against hospitalization for RSV lower respiratory tract infection in infants. A new long-acting monoclonal antibody against RSV infection, having shown excellent
\end{abstract}

Correspondence to: Professor Demetrios A. Spandidos, Laboratory of Clinical Virology, School of Medicine, University of Crete, 71003 Heraklion, Greece

E-mail: spandidos@spandidos.gr

Key words: Paediatric Virology, respiratory syncytial virus, medical education, vaccines, antiviral agents, Simon B. Drysdale promise in a Phase 2 trial in infants, is about to be investigated in a Phase 3 clinical trial commencing shortly.

\section{Contents \\ 1. Introduction \\ 2. Questions and Answers}

\section{Introduction}

Born in London in the United Kingdom (UK) in 1978, Dr Simon B. Drysdale (Fig. 1) is a Consultant and Honorary Senior Lecturer in Paediatric Infectious Diseases (PID) at St. George's University Hospital NHS Foundation Trust and St. George's, University of London, UK. He graduated from St. George's Hospital Medical School in 2003, undertook a PhD at King's College London from 2008-2011 (1) and completed his postgraduate diploma in PID at the University of Oxford in 2016. He has published >50 articles, book chapters and commentaries on the topics of PID and General Paediatrics; among these 33 are indexed in PubMed (2-34). He received the Infectious Diseases Society of America (IDSA) Young Investigator award in 2010 and a prestigious Advances Immunization Technologies (ADITEC) Fellowship to attend the 18th Advanced Course of Vaccinology (ADVAC) in Annecy, France in 2017.

Dr Drysdale's main research interest is respiratory syncytial virus (RSV) and other respiratory virus infections. He is particularly interested in understanding the host susceptibility to RSV, but also in the management of RSV infection and associated health economics and the development of treatments and immunisations/vaccines, which are currently lacking. He is currently involved in research ranging from basic sciences through to clinical trials - 'bench to bedside'.

$\mathrm{He}$ is an investigator on the European Union/Innovative Medicines Initiative (EU/IMI) funded 'Respiratory Syncytial Virus Consortium in Europe' (RESCEU) project, a large European-wide collaboration of researchers interested in RSV infection. The aim of the clinical studies is to identify biomarkers that will predict RSV disease severity or sequelae and improve 
the understanding of RSV epidemiology. Dr Drysdale has also been an investigator on several industry-funded clinical trials relating to RSV treatments or prophylactic agents. In addition to respiratory viral infections, Dr Drysdale is also interested in antimicrobial stewardship and was a member of the Antimicrobial, Resistance and Prescribing in European Children/Global Antimicrobial Resistance, Prescribing and Efficacy among neonates and Children (ARPEC/GARPEC) collaboration from the outset, contributing data for several publications. He has also been the principal investigator of industry-funded clinical trials investigating the use of new antibiotics in children and has been involved in studies on topics including cytomegalovirus (CMV) infection, influenza vaccines, immunoglobulin treatment for encephalitis and antifungal use in children. In addition, Dr Drysdale functions as a reviewer for several funding bodies, including the National Institute for Health Research (NIHR) and is a peer reviewer for multiple scientific journals.

On October 12th, 2019, Dr Drysdale will chair the ' 5 th workshop on Paediatric Virology' organized by the Paediatric Virology Study Group (PVSG) (35) and his plenary lecture will focus on the new advances and challenges on the management of RSV infection in children. During the ' 5 th workshop on Paediatric Virology', Dr Drysdale will receive the PVSG's '2019 Paediatric Virology Award' for his outstanding academic contribution in the field of paediatric viral infectious diseases.

\section{Questions and Answers}

Question: First of all, thank you for agreeing to chair our workshop on Paediatric Virology, which this year will focus on RSV, which is the most important cause of hospitalization in infants and one of the leading global causes of infant mortality. RSV or 'human orthopneumovirus'? Which term do you prefer?

Answer: I prefer the term RSV, which is very well established and understood by healthcare professionals, students, scientists and the public. Human orthopneumovirus is the relatively new species name for RSV. The virus name remains RSV.

Question: In one of your recent articles you note a paucity of epidemiological data on RSV in different settings and age groups and limited knowledge about the health-care costs of RSV infection. What data is still needed?

Answer: While there are plenty of RSV epidemiological and healthcare cost data available for young infants and children, that for older children (e.g., >5 years old) and adults is lacking. More data is required in these groups, in particular in older adults, where emerging data suggests RSV is a significant cause of morbidity and mortality. In addition, as significant developments are being made in maternal RSV vaccines to protect infants, more data on the burden of RSV infection in pregnant women is required. These data are needed in primary and secondary care settings.

Question: Neonatal prematurity is considered the most significant risk factor for the severity of RSV infection. However, it is not yet clear why some infants infected with RSV develop lower respiratory tract infection, while others do not. How significant is the role of genetic predisposition?

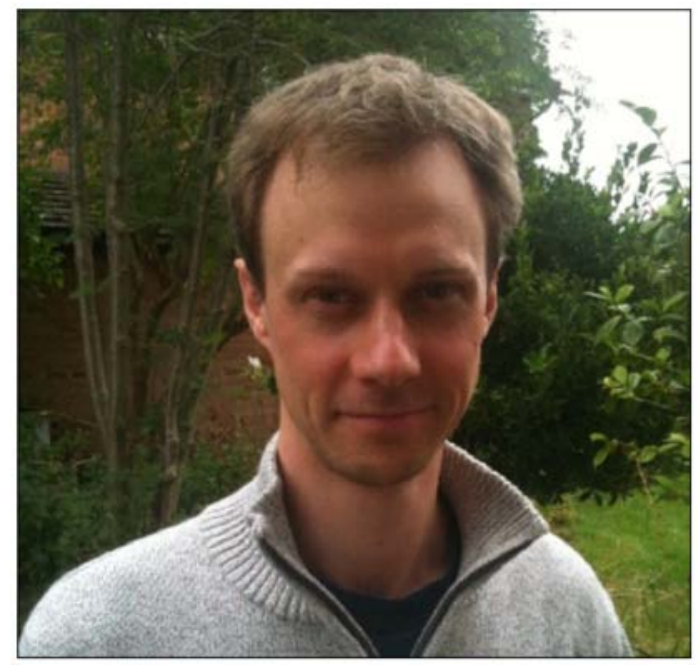

Figure 1. Dr Simon B. Drysdale, Consultant and Honorary Senior Lecturer in Paediatric Infectious Diseases at St. George's University Hospital NHS Foundation Trust and St. George's University of London, UK and Chair of the '5th workshop on Paediatric Virology', Saturday, October 12, 2019.

Answer: Several genes and single nucleotide polymorphisms have been shown to be associated with an increased susceptibility to severe RSV infection in infants. However, many other factors are also involved, such as age at exposure to RSV, RSV viral load, maturity of the immune system, co-morbidities and functional aspects (e.g., lung function). It is not yet clear how all these factors fit together.

Question: RSV testing can increase our clinical confidence to withhold empirical antibiotics; however, there is limited evidence for this in clinical practice. In infants requiring hospital admission, RSV testing allows infection control management to minimize nosocomial transmission. What is the clinical usefulness of RSV testing in primary care and emergency departments?

Answer: Generally, there is little use in testing for RSV or other respiratory viruses in primary care as management is based on the clinical syndrome not the results of a viral test. There is, however, some data that suggest that respiratory viral testing improves parent satisfaction and doctor confidence in the diagnosis, although more studies are needed on this topic. In emergency departments, for those patients being discharged, with regards to viral testing, the same is true as for primary care. In those likely to be admitted to hospital, respiratory virus testing allows the earlier cohorting of patients and thus reduces the risk of nosocomial infection.

Question: What are the most recent advances concerning the therapeutic management options of children infected with RSV?

Answer: There are currently several antiviral medications to treat RSV infection in development, although none have yet progressed beyond Phase 2 clinical trials. Only five of these studies include children. Multiple types of novel therapeutic molecules have been developed, including fusion and non-fusion inhibitors and polymerase inhibitors aimed at various RSV targets, such as the F protein and RNA polymerase. The role of ribavirin used in conjunction with intravenous immuno- 
globulin in immunosuppressed children with RSV infection is also being explored.

Question: We definitely need new therapies, but we also need a vaccine against RSV; there is currently no licensed vaccine to prevent RSV infection, but passive immunoprophylaxis using Palivizumab. What are the current perspectives for a new vaccine against RSV?

Answer: Great strides have been made in recent years with regards to an RSV vaccine or new monoclonal antibody, with more than 40 candidates currently in development. A maternal RSV vaccine has just completed a Phase 3 trial and had $44 \%$ efficacy against hospitalization for RSV lower respiratory tract infection in infants. A pathway to licensure is being investigated. A new long acting monoclonal antibody against RSV infection, having shown excellent promise in a Phase 2 trial in infants, is about to be investigated in a Phase 3 clinical trial starting shortly.

Question: There is a wide variation in the management of infants with RSV-positive bronchiolitis in different countries, as well as in different hospitals, even in the same geographical area. This leads to the inappropriate use of bronchodilators, nebulised hypertonic saline and antibiotics in children with RSV infection. How difficult is it to establish and implement into the clinical practice clinical guidelines targeting RSV bronchiolitis?

Answer: It is easy relatively to develop clinical guidelines, but implementing them and getting clinicians to follow them is often problematic. Studies investigating the adherence to bronchiolitis guidelines show widespread inappropriate use of therapies for which there is no evidence of benefit despite clear guidance not to use them. Widely distributing educational materials, regular national surveys and local audits are useful in helping adopt new guidelines into routine clinical practice.

Question: Among the notable alumni in your university was Dr Edward Jenner, the 'father of Immunology', a country doctor who would eventually become one of the most famous scientists in the world. We would like your comment on his contribution in Medicine.

Answer: Edward Jenner was the one of the first people to recognise the principle of vaccination, leading him to inoculate a young child with cowpox to prevent disease with the more severe human disease smallpox. In so 'inventing' vaccination, his work has probably resulted in the saving of more lives than almost anyone else in history.

Question: The term 'vaccination' derived from the Latin word 'vacca' was created to describe Dr Edward Jenner's inoculation of pustular material obtained from lesions on cows affected by cow-pox. This term later on was adopted to mean immunization against any disease. Is this a 'good' term? Is this a medical term that cause confusion or misunderstanding?

Answer: The World Health Organisation (WHO) definition of a vaccine is: 'A biological preparation that improves immunity to a particular disease' and 'vaccination' is the process by which the vaccine is administered. As with any medical term there is the potential for confusion and misunderstanding around what the term means. It is, therefore, up to governments, health authorities/agencies, healthcare workers, etc., to ensure these misconceptions are minimised as much as possible. This will ensure as many people as possible can be appropriately vaccinated preventing potentially avoidable infections.

Question: In 2015, Paediatric Virology was proposed as a separate paediatric subspecialty candidate. This proposal was met with enthusiasm, since in the future paediatric virologists are expected to play a crucial clinical, academic and research role consulting nationally on complicated viral infections, undertaking medical education for paediatric trainees and highlighting new priorities in Virology research for neonates and children. How would you evaluate this role of Paediatric Virology in future Medicine?

Answer: At present subspecialists in PID, general paediatricians with an interest in infectious diseases or adult virologists manage children with complex viral infections (e.g., HIV, congenital $\mathrm{CMV}$, hepatitis $\mathrm{B} / \mathrm{C}$ ). There may be a significant role for specialists in Paediatric Virology in the future, but the training pathway towards a Consultant post would need to be carefully planned.

Question: What are the current training options (postgraduate training, subspecialty, $\mathrm{PhD}, \mathrm{MSc}$, Diplomas) in the $\mathrm{UK}$ for a paediatric trainee, who is interested in paediatric viral infections? What new educational tools would you propose for medical education of paediatric health trainees and professionals on recent advances on Paediatric Virology (e.g., twitter, facebook, e-books, webinars)?

Answer: In the UK, clinical training in Paediatric Virology can be undertaken by entering subspecialty training in PID or being a general paediatrician and undertaking a special interest (SPIN) module in infectious diseases. The Royal College of Paediatrics and Child Health (RCPCH) in the UK, currently, has a subspecialty group comprising allergy, immunology and infectious diseases. In addition, it is possible to do a higher degree, e.g., Masters of Sciences (MSc), Doctor of Philosophy (PhD), Master of Research (MRes), or a Diploma, such as the Postgraduate Diploma in Paediatric Infectious Diseases run by the University of Oxford. Online courses or webinars, which can be undertaken by students in their own time, are becoming increasingly popular. Social media is another way to keep abreast of current updates in viral infections. I regularly use Twitter to tweet about respiratory viral infections; follow me at @sbdrysdale.

Question: On behalf of the PVSG, I have the great honour to announce you as the recipient of the '2019 Paediatric Virology Award' for your outstanding academic contribution in the field of paediatric viral infectious diseases. What are the most significant developments in the rapidly increasing educational challenge of Paediatric Virology over the past decade?

Answer: I am very honoured and privileged to be awarded the '2019 Paediatric Virology Award'. There have been many advancements in the field of paediatric viral infections over the last few years. The management of infants with congenital CMV infection in particular, has changed a lot. From only treating the most severely affected who were clearly symptomatic at birth, we now treat many more mildly affected infants 
improving their outcomes, especially in relation to hearing and speech and language development.

Question: You are considered as one of the most talented PID early career academic specialists in the UK, having the chance to perform interesting studies and work with top paediatric experts, such as Professor Anne Greenough, our 'Queen in Neonatology'. Which value/virtue is the most important in your paediatric career?

Answer: I think perseverance and the power to never give up is of critical importance. Whether you are a clinician or researcher, having the ability to pick yourself up and keep going after a failure is essential to get where you want to be.

Question: Thank you for your very interesting answers and we wish you the best in your clinical, research and academic state-of-the-art contribution. We look forward to your chairship of our workshop as well your plenary lecture and we thank you for your help and your support to the PVSG.

\section{Acknowledgements}

This article is published in the third supplement issue of the Experimental and Therapeutic Medicine, which is dedicated to Paediatric Virology. This edition is performed in the context of the '5th workshop on Paediatric Virology' (Sparta, Greece, October 12, 2019) organized by the Paediatric Virology Study Group (PVSG) and supported by the Department of Clinical Virology of the University of Crete School of Medicine and the First Department of Paediatrics of the University of Athens School of Medicine. We would like to thank Dr Simon B. Dryslade for this educational and inspirational interview-style article. We would also like to thank all the members of the PVSG for their interesting questions to Dr Drysdale and their valuable comments.

\section{References}

1. Drysdale SB: Diminished lung function, viral infections and chronic respiratory morbidity in prematurely born infants (PhD Thesis). King's College London, London, 2014.

2. Sande CJ, Njunge JM, Mwongeli Ngoi J, Mutunga MN, Chege T, Gicheru ET, Gardiner EM, Gwela A, Green CA, Drysdale SB, et al: Airway response to respiratory syncytial virus has incidental antibacterial effects. Nat Commun 10: 2218, 2019.

3. Johnstone PD, Jayamohan J, Kelly DF and Drysdale SB: Does appendicitis in a child with a ventriculoperitoneal shunt necessitate shunt revision? Arch Dis Child 104: 607-609, 2019.

4. Barr R, McGalliard R and Drysdale SB: Human metapneumovirus in paediatric intensive care unit (PICU) admissions in the United Kingdom (UK) 2006-2014. J Clin Virol 112: 15-19, 2019.

5. Lin GL, McGinley JP, Drysdale SB and Pollard AJ: Epidemiology and Immune Pathogenesis of Viral Sepsis. Front Immunol 9: 2147,2018

6. Drysdale SB and Kelly DF: How to use...respiratory viral studies. Arch Dis Child Educ Pract Ed: Aug 28, 2018 (Epub ahead of print).

7. Barr R, Carande EJ, Pollard AJ and Drysdale SB: Change in viral bronchiolitis management in hospitals in the UK after the publication of NICE guideline. J Clin Virol 105: 84-87, 2018.

8. MacBean V, Lunt A, Drysdale SB, Yarzi MN, Rafferty GF and Greenough A: Predicting healthcare outcomes in prematurely born infants using cluster analysis. Pediatr Pulmonol 53: 1067-1072, 2018.

9. Carande EJ, Galiza EP, Nickless A, Pollard AJ and Drysdale SB: Viral bronchiolitis management in hospitals in the UK. J Clin Virol 104: 29-33, 2018.
10. Versporten A, Zarb P, Caniaux I, Gros MF, Drapier N, Miller M, Jarlier V, Nathwani D, Goossens H, Koraqi A, et al; Global-PPS network: Antimicrobial consumption and resistance in adult hospital inpatients in 53 countries: Results of an internet-based global point prevalence survey. Lancet Glob Health 6: e619-e629, 2018.

11. Carande EJ, Cheung CR, Pollard AJ and Drysdale SB: Change in viral bronchiolitis management in primary care in the UK after the publication of NICE guideline. Thorax: Jan 9, 2018 (Epub ahead of print).

12. MacBean V, Drysdale SB, Yarzi MN, Peacock JL, Rafferty GF and Greenough A: Respiratory viral infections in infancy and school age respiratory outcomes and healthcare costs. Pediatr Pulmonol 53: 342-348, 2018.

13. Drysdale SB, Mejias A and Ramilo O: Rhinovirus - not just the common cold. J Infect 74 (Suppl 1): S41-S46, 2017.

14. Robey RC, Drysdale SB, Kelly DF, Bowler IC and Sadarangani M: Age-specific trends in antibiotic resistance in Escherichia coli infections in Oxford, United Kingdom 2013-2014. J Infect 74: 195-198, 2017.

15. Drysdale SB and Pollard AJ: Intussusception risk after rotavirus vaccination in England. Vaccine 34: 6114, 2016.

16. Carande EJ, Pollard AJ and Drysdale SB: Management of Respiratory Syncytial Virus Bronchiolitis: 2015 Survey of Members of the European Society for Paediatric Infectious Diseases. Can J Infect Dis Med Microbiol 2016: 9139537, 2016.

17. Drysdale SB and Kelly DF: Fifteen-minute consultation: Enterovirus meningitis and encephalitis-when can we stop the antibiotics? Arch Dis Child Educ Pract Ed 102: 66-71, 2017.

18. Drysdale SB, Alcazar M, Wilson T, Smith M, Zuckerman M, Hodemaekers HM, Janssen R, Bont L, Johnston SL and Greenough A: Functional and genetic predisposition to rhinovirus lower respiratory tract infections in prematurely born infants. Eur J Pediatr 175: 1943-1949, 2016.

19. Drysdale SB, Green CA and Sande CJ: Best practice in the prevention and management of paediatric respiratory syncytial virus infection. Ther Adv Infect Dis 3: 63-71, 2016.

20. Versporten A, Bielicki J, Drapier N, Sharland M and Goossens H; ARPEC project group: The Worldwide Antibiotic Resistance and Prescribing in European Children (ARPEC) point prevalence survey: Developing hospital-quality indicators of antibiotic prescribing for children. J Antimicrob Chemother 71: 1106-1117, 2016.

21. Drysdale SB, Sande CJ, Green CA and Pollard AJ: RSV vaccine use - the missing data. Expert Rev Vaccines 15: 149-152, 2016.

22. Drysdale SB and Pollard AJ: Group B meningococcal vaccine science and policy. J Infect 71 (Suppl 1): S15-S20, 2015.

23. Drysdale SB, Alcazar-Paris M, Wilson T, Smith M,Zuckerman M, Peacock JL, Johnston SL and Greenough A: Viral lower respiratory tract infections and preterm infants' healthcare utilisation. Eur J Pediatr 174: 209-215, 2015.

24. Drysdale SB, Lo J, Prendergast M, Alcazar M, Wilson T, Zuckerman M, Smith M, Broughton S, Rafferty GF, Peacock JL, et al: Lung function of preterm infants before and after viral infections. Eur J Pediatr 173: 1497-1504, 2014.

25. Drysdale SB, Alcazar M, Wilson T, Smith M, Zuckerman M, Lauinger IL, Tong CY, Broughton S, Rafferty GF, Johnston SL, et al: Respiratory outcome of prematurely born infants following human rhinovirus $\mathrm{A}$ and $\mathrm{C}$ infections. Eur $\mathrm{J}$ Pediatr 173: 913-919, 2014.

26. Drysdale SB, Prendergast M, Alcazar M, Wilson T, Smith M, Zuckerman M, Broughton S, Rafferty GF, Johnston SL, Hodemaekers HM, et al: Genetic predisposition of RSV infection-related respiratory morbidity in preterm infants. Eur J Pediatr 173: 905-912, 2014.

27. Versporten A,Sharland M,Bielicki J, Drapier N, Vankerckhoven V and Goossens H; ARPEC Project Group Members: The antibiotic resistance and prescribing in European Children project: A neonatal and pediatric antimicrobial web-based point prevalence survey in 73 hospitals worldwide. Pediatr Infect Dis J 32: e242-e253, 2013.

28. Drysdale SB, Alcazar-Paris M,Wilson T, Smith M,Zuckerman M, Broughton S, Rafferty GF, Peacock JL, Johnston SL and Greenough A: Rhinovirus infection and healthcare utilisation in prematurely born infants. Eur Respir J 42: 1029-1036, 2013.

29. Drysdale SB, Milner AD and Greenough A: Respiratory syncytial virus infection and chronic respiratory morbidity - is there a functional or genetic predisposition? Acta Paediatr 101: 1114-1120, 2012. 
30. Drysdale SB, Alcazar M, Wilson T, Smith M, Zuckerman M Wedderburn CJ, Broughton S, Rafferty GF, Johnston SL and Greenough A: Pandemic influenza A (H1N1) virus 2009 in a prospectively followed cohort of prematurely born infants. Pediatr Infect Dis J 31: 91-92, 2012.

31. Drysdale SB, Wilson T, Alcazar M, Broughton S, Zuckerman M, Smith M, Rafferty GF, Johnston SL and Greenough A: Lung function prior to viral lower respiratory tract infections in prematurely born infants. Thorax 66: 468-473, 2011.

32. Drysdale SB, Coulson T, Cronin N, Manjaly ZR, Piyasena C, North A, Ford-Adams ME and Broughton S: The impact of the National Patient Safety Agency intravenous fluid alert on iatrogenic hyponatraemia in children. Eur J Pediatr 169: 813-817, 2010 .
33. Newell B, Bedlow AJ, Cliff S, Drysdale SB, Stanton AW and Mortimer PS: Comparison of the microvasculature of basal cell carcinoma and actinic keratosis using intravital microscopy and immunohistochemistry. Br J Dermatol 149: 105-110, 2003.

34. Stanton AW, Drysdale SB, Patel R, Mellor RH, Duff MJ, Levick JR and Mortimer PS: Expansion of microvascular bed and increased solute flux in human Basal cell carcinoma in vivo, measured by fluorescein video angiography. Cancer Res 63: 3969-3979, 2003.

35. Mammas IN, Theodoridou M and Spandidos DA: The development of the Paediatric Virology Study Group: Ten years in the making. Exp Ther Med 13: 363, 2017.

(i) (9) This work is licensed under a Creative Commons Attribution-NonCommercial-NoDerivatives 4.0 International (CC BY-NC-ND 4.0) License. 